\title{
Sub-surface melting in a seasonal snow cover
}

\author{
GARY KOH AND RACHEL JORDAN \\ U.S. Army Cold Regions Research and Engineering Laboratory, Hanover, New Hampshire 03755, U.S.A.
}

\begin{abstract}
The ability of solar radiation to penetrate into a snow cover combined with the low thermal conductivity of snow can lead to a sub-surface temperature maximum. This elevated sub-surface temperature allows a layer of wet snow to form below the surface even on days when the air temperature remains subfreezing. A high-resolution frequency-modulated continuous wave (FMCW) radar has been used to detect the onset of sub-surface melting in a seasonal snow cover. The experimental observation of sub-surface melting is shown to be in good agreement with the predictions of a one-dimensional mass- and energy-balance model. The effects of varying snow characteristics and solar extinction parameters on the sub-surface melt characteristics are investigated using model simulations.
\end{abstract}

\section{INTRODUCTION}

The study of the physical processes that occur near the surface of a seasonal snow cover is complicated by diurnal variations in the surface-energy balance, resulting primarily from swings in air temperature and solar radiation. This was illustrated by Colbeck (1989), who modeled the temperature profile in a seasonal snow cover by assuming a sinusoidally varying surface temperature and exponential decay of solar radiation within the snow cover. His calculations showed that a sub-surface temperature maximum can occur, if the rate of solar heating beneath the snow surface is greater than the rate of cooling by conduction. A more refined energytransport calculation at the snow surface was conducted by Brandt and Warren (1993) to illustrate that the elevated sub-surface temperature in high-density Antarctic snow reported and modeled by Schlatter (1972) may be in error. They refined the model of Schlatter (1972) by using a narrow spectral resolution for solar radiation to take into account the wavelength-dependent extinction in snow. The narrow-band model indicated that the broadband approximation used by both Schlatter (1972) and Colbeck (1989) overestimates the magnitude and depth of the sub-surface maximum and that, for clean snow, significant sub-surface temperature elevations are limited to low-density snow covers. Other researchers (Marshall and Warren, 1987; Brun and others, 1989; Jordan, 1991; Greuell and Konzelmann, 1994) have used two- or threeband models that offer significant improvement over the one-band variety without the computational inefficiency of fine spectral resolution. Brun and others (1989) observed the occurrence of temperature maxima a few centimeters below the snow surface on cold, sunny days and successfully replicated measured temperature profiles using a three-band model divided at wavelengths of 0.8 and $0.15 \mu \mathrm{m}$.

The modeled results of the elevated sub-surface temperature effects have been difficult to verify experimentally. This is primarily due to the difficulties involved in measuring the temperature profile of a snow cover using temperature sensors embedded in snow. Radiative heating of these sensors on clear days can lead to incorrect temperature measurements (Brandt and Warren, 1993). More conclusive evidence of elevated sub-surface temperatures may be the onset of sub-surface melting, which can be easily detected using a high-resolution frequencymodulated continuous wave (FMCW) radar. FMCW radars have the characteristics of detecting layers within a snow cover, if sufficient electromagnetic contrast exists between the layers, arising from discontinuities in dielectric constant, snow grain-size and/or surface roughness. The large dielectric contrast between ice and water at the radar frequencies makes it possible to detect subsurface melting with an FMCW radar.

We have recently observed that sub-surface melting is not an uncommon event in a seasonal snow cover. In this paper, a case study is presented of a sub-surface melting event observed with an FMCW radar. A one-dimensional mass- and energy-balance model for snow (SNTHERM), developed by Jordan (1991), is used to predict the temperature and liquid-water content profiles of the snow cover. The solar absorption routine in SNTHERM uses a simple two-band resolution of the solar spectrum $(0.4$ $1.12 \mu \mathrm{m}$ and $1.12-2.4 \mu \mathrm{m})$, in which the longer-wavelength component is "dumped" at the surface and the shorter-wavelength fraction is absorbed exponentially. The experimental observations of sub-surface melt are shown to be in good agreement with the modeled results. These encouraging results gave us confidence to run additional simulations in order to test the effects of varying snow characteristics and solar-extinction parameters on the sub-surface melt characteristics. The simulations indicated that the occurrence of sub-surface melt is strongly dependent on snow density and generally concurred with the observation of Brandt and Warren 
(1993) that sub-surface temperature elevations are minimal in high-density snow.

The ability to detect and model the sub-surface melt in a seasonal snow cover can contribute to a better understanding of the physical processes that occur near the snow surface. Practical applications of these subsurface effects may be found in snow remote-sensing and avalanche investigations. Microwave interaction with a snow cover is greatly influenced by the presence of liquid water; therefore the conditions that can lead to an increase or decrease in snow wetness are of considerable interest to the radar remote-sensing community. Prediction of avalanche releases may be improved by investigating the processes that contribute to the formation of mechanically weak snow layers. Avalanche releases have been attributed to layers of depth hoar (Akitaya and Shimizu, 1987) and wet snow (Izumi, 1989) which were buried by subsequent snowfalls. It is possible that subsurface melting and subsequent freezing of this melted layer can also affect the mechanical strength of the snow below the surface.

\section{EXPERIMENT}

\section{a. Environmental conditions}

A case study of the FMCW radar observation of subsurface melting that began around $1230 \mathrm{~h}$ on 1 March 1993 in Hanover, New Hampshire, is presented. The subsurface melting was observed on a calm, clear day when the air temperature was below freezing. Figure 1 presents some of the relevant meteorological conditions during the onset of melting. The air temperature remained subfreezing for most of the day except between 1400 and $1800 \mathrm{~h}$ the maximum temperature of $2.8^{\circ} \mathrm{C}$ was observed around $1600 \mathrm{~h}$ ). During this period, the hourly averaged wind speed ranged between 1 and $3 \mathrm{~ms}^{-1}$. The incoming solar radiation measured with a pyranometer indicated that the sky was relatively free of clouds during the onset of sub-surface melting. The fractional cloud cover reported at an airport 6 miles $[9.6 \mathrm{~km}]$ to the south confirmed the measurements of the pyranometer.

The snow-cover properties were obtained from snow pits located approximately $5 \mathrm{~m}$ from the radar footprint. The snow cover consisted of several layers whose total
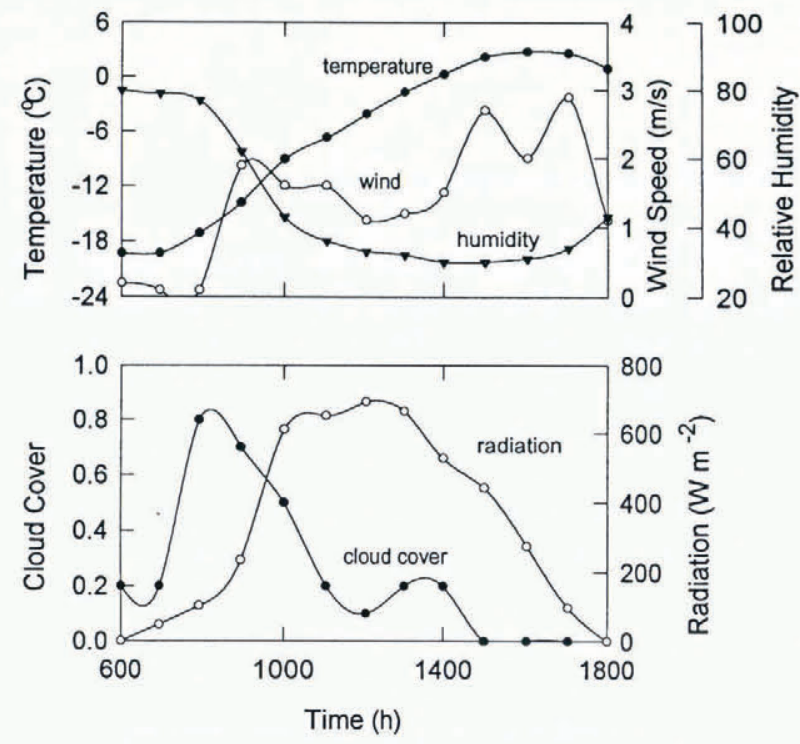

Fig. 1. Hourly summaries of the meteorological conditions during the onset of sub-surface melting.

depth was approximately $30-40 \mathrm{~cm}$ (due to the uneven contour of the radar plot, there was some spatial variability). Profiles of the snow temperature, density and grain-size observed at $0900 \mathrm{~h}$ are reported in Table 1. The thermal conductivity and effective thermal conductivity are computed from algorithms within the computer simulation to be discussed later. The snow temperature was obtained by inserting at varying depths a single thermocouple probe that was attached to a digital thermometer. The temperature of the entire snow cover was sub-freezing and had a negative gradient due to overnight radiative cooling of the surface.

The top $4 \mathrm{~cm}$ of the snow cover fell on 22-23 February and by 1 March had densified to $130 \mathrm{~kg} \mathrm{~m}^{3}$. Below the top layer was the remains of $20 \mathrm{~cm}$ of snow that fell on $16-$ 17 February, which had compacted to approximately $15 \mathrm{~cm}$ and had a density of $170 \mathrm{~kg} \mathrm{~m}^{-3}$. The snow grainsize of the top two layers was approximately $0.5 \mathrm{~mm}$. The bottom third of the snow cover consisted of a $2 \mathrm{~cm}$ crust on top of approximately $10-20 \mathrm{~cm}$ of snow. This layer was created by the snowfall of 12-13 February, when approximately $20 \mathrm{~cm}$ of snow fell over an existing shallow snow cover. During the latter part of this storm, the snow

Table 1. Initial snow-cover characteristics and control-volume grid used in computer simulation for 1 March 1993

\begin{tabular}{|c|c|c|c|c|c|c|}
\hline Top of layer & Layer thickness & Snow temperature & Snow density & Grain-size & $\begin{array}{c}\text { Thermal } \\
\text { conductivity }\end{array}$ & $\begin{array}{c}\text { Effective thermal } \\
\text { conductivity }\end{array}$ \\
\hline $\mathrm{cm}$ & $\mathrm{cm}$ & ${ }^{\circ} \mathrm{C}$ & $\mathrm{kg} \mathrm{m}^{-3}$ & $\mathrm{~mm}$ & $\mathrm{Wm}^{-1} \mathrm{~K}^{-1}$ & $W m^{-1} K^{-1}$ \\
\hline 34 & 4 & -10.6 & 130 & 0.5 & 0.088 & 0.171 \\
\hline 30 & 15 & $\begin{array}{c}-9.19 \text { (top) } \\
-2.5 \text { (bottom })\end{array}$ & 170 & 0.5 & 0.125 & 0.205 \\
\hline 15 & 2 & - & 600 & 1.0 & 1.028 & 1.093 \\
\hline 13 & 13 & $\begin{array}{c}-2.2 \text { (top) } \\
-1.1 \text { (bottom) }\end{array}$ & 250 & 1.5 & 0.223 & 0.301 \\
\hline
\end{tabular}


was wet and formed the crust when it subsequently froze. The density of the bottom layer was approximately $250 \mathrm{~kg} \mathrm{~m}^{-3}$.

\section{b. FMCW radar measurements}

The FMCW radar system that was used to detect subsurface melting is illustrated in Figure 2. An HP 8350B sweep oscillator and an HP 83554A millimeter-wave source module generates signals whose frequency varies linearly with time from 26.5 to $40 \mathrm{GHz}$ with a sweep time of $80 \mathrm{~ms}$. A directional coupler divides the frequencymodulated signal into two paths; a reference signal is brought directly into the mixer (directional coupler and

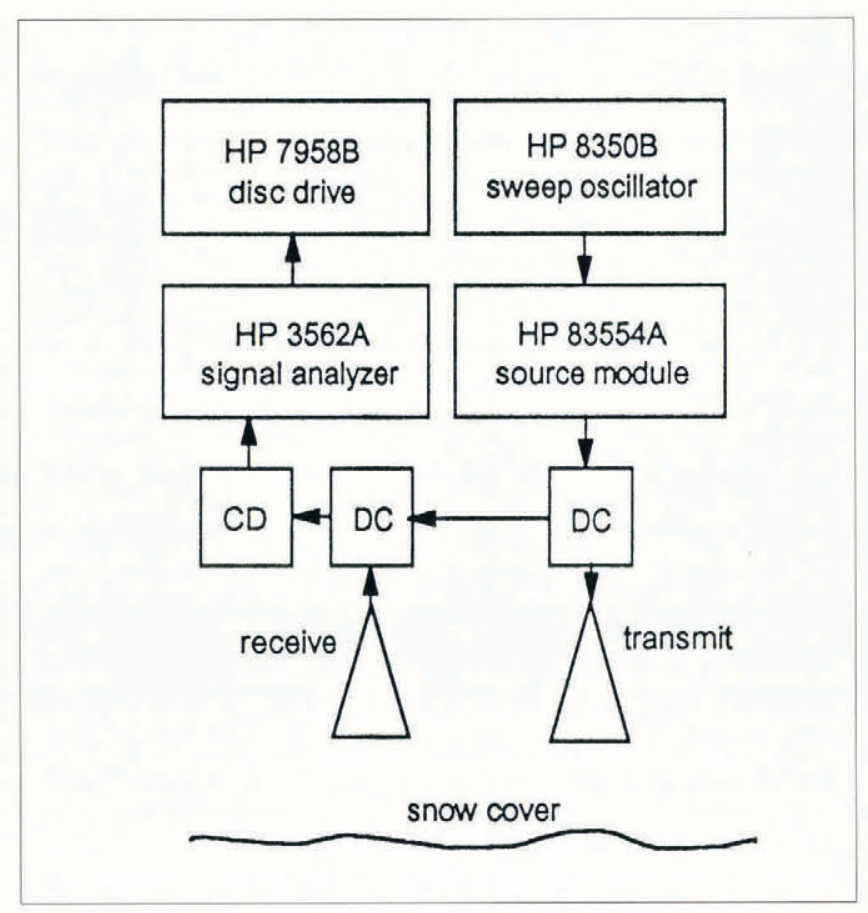

Fig. 2. Schematic of the FMCW radar. DC and CD are directional coupler and crystal detector, respectively.

crystal detector) and a target signal is routed to the snow cover via a transmitting antenna. The reflected signal from the snow cover is fed into the mixer input via a receiving antenna. An HP 3562A signal analyzer is used to obtain the fast Fourier transform (FFT) of the mixer output. The FFT yields a power spectrum where the frequency is proportional to the return travel time (function of the target distance and the effective dielectric constant of the propagation path) of the source signal and whose magnitude is proportional to the target reflectivity. An example of a power spectrum, illustrating the output of an FMCW radar, is illustrated in Figure 3. The first peak in the power spectrum at $6.012 \mathrm{kHz}$ represents the reflection from the snow surface. The second peak at $6.248 \mathrm{kHz}$ represents the reflection from the crust approximately $19 \mathrm{~cm}$ below the surface. For the FMCW radar system used in this study, the relations between the distance within the snow, $\Delta Z(\mathrm{~cm})$, and the frequency difference in the power spectrum, $\Delta f(\mathrm{~Hz})$, is expressed as
Snow Depth $(\mathrm{cm})$

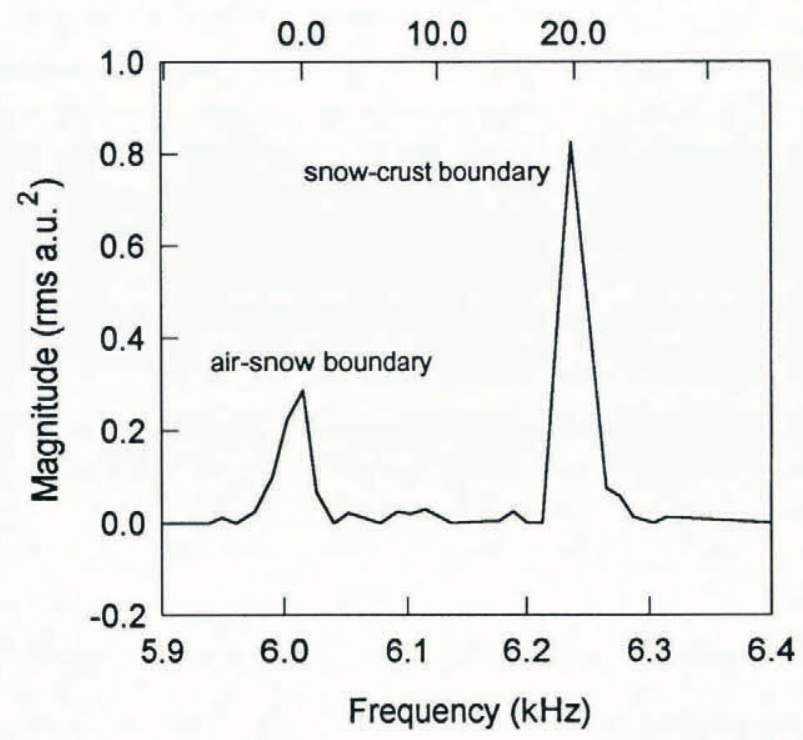

Fig. 3. FMCW radar output. The frequency of the power spectrum is proportional to the electromagnetic distance and the magnitude is proportional to the larget reflectivity.

$$
\Delta Z=\frac{\Delta f t_{\mathrm{swp}} c}{2 b w \sqrt{\epsilon_{\mathrm{eff}}}}
$$

where $t_{\mathrm{swp}}$ is the sweep rate $(80 \mathrm{~ms}), b w$ is the band width of the FMCW sweep $(13.5 \mathrm{GHz}), c$ is the velocity of light and $\epsilon_{\text {eff }}$ is the effective dielectric constant of snow. For a record length of $80 \mathrm{~ms}$, the signal analyzer has a frequency resolution of $12.5 \mathrm{~Hz}$, which corresponds to a resolution of approximately $1 \mathrm{~cm}$ in low-density snow.

For this study, the FMCW radar was mounted on a gantry approximately $6 \mathrm{~m}$ above the ground (the distance between the base of the antenna and the ground was $5.6 \mathrm{~m}$ ) and positioned so that the transmitted signal was directed toward the snow cover at a $4^{\circ}$ incident angle. The radar back-scatter from the same spot on the snow cover was recorded once every $30 \mathrm{~min}$. A sequence of FMCW radar returns illustrating the formation of a water layer beneath the snow surface is shown in Figure 4. The return at $1210 \mathrm{~h}$ is very similar to that observed at 0910 h (cf. Fig. 3), indicating that very little change in snow property occurred during the $4 \mathrm{~h}$ period between these two traces. The formation of a melt layer beneath the snow surface began to emerge around $1240 \mathrm{~h}$ until a distinct layer was detected around $1310 \mathrm{~h}$. The frequency difference between these two peaks was $0.025 \mathrm{kHz}$. For snow, whose density is $130 \mathrm{~kg} \mathrm{~m}^{-3}$ (effective dielectric constant of approximately 1.28 ), this frequency difference indicates that the top of the melt layer occurred approximately $2.0 \mathrm{~cm}$ below the surface the thickness of the melt layer cannot be inferred from the radar measurement). Application of water-sensitive dye to the snow below the surface confirmed that a layer of wet snow due to sub-surface melting was present.

Further analysis of the radar data indicated that the maximum melt appeared to have occurred around $1400 \mathrm{~h}$. The increase in liquid water resulted in higher absorption loss, so that the magnitude of the reflection from the crust was at its minimum. After $1440 \mathrm{~h}$, the 

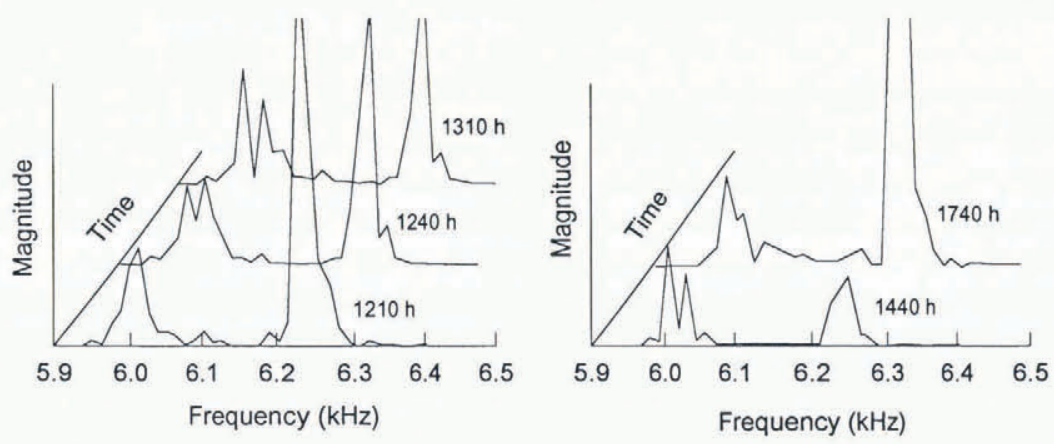

Fig. 4. Sequence of FMCW radar response illustrating the formation of a melt layer below the snow surface.

magnitude of the reflection from the crust layer gradually increased, which indicated that the melted layer had begun to freeze. The reflection from the crust gradually increased and then stabilized after $1740 \mathrm{~h}$, which indicated that liquid water was no longer present. Comparison of the FMCW radar returns from 0910 and $1740 \mathrm{~h}$ shows that, due to the sub-surface melt and freeze cycle, the FMCW radar was able to detect a refrozen layer that was not present before the melt.

The ability to detect sub-surface melting with an FMCW radar has been demonstrated. The FMCW radar provides information about the time and location of the melt layer. To investigate the physical processes responsible for the sub-surface melt, the radar data are analyzed using a one-dimensional heat- and massbalance model.

\section{NUMERICAL MODEL}

Conservation of energy for a one-dimensional snowsoil system is described by the partial differential equation

$$
c_{\mathrm{s}} \rho_{\mathrm{s}} \frac{\partial T}{\partial t}+M L_{\mathrm{m}}=\frac{\partial}{\partial z}\left(k_{\mathrm{e}} \frac{\partial T}{\partial z}\right)-\frac{\partial F_{\mathrm{solar}}}{\partial z}
$$

where $c_{\mathrm{s}}$ is the effective heat capacity of the wet snow, $\rho_{\mathrm{s}}$ is the snow density, $T$ is temperature (Kelvin), $M$ is the rate of phase change (or melt) from ice to liquid, $L_{\mathrm{m}}$ is the latent heat of fusion, $t$ is time, $k_{\mathrm{e}}$ is an effective thermal conductivity, $F_{\text {solar }}$ is the net solar radiation positive upwards) and $z$ is the vertical position measured upwards from the snow-soil interface. Convected heat resulting from water flow is not included in Equation (2), since the liquid-water content in this application does not reach the minimum level necessary for flow. Sensible- and latentheat effects are combined in an apparent heat capacity, which incorporates a freezing curve for snow artificially selected so that it approaches a step function at $0^{\circ} \mathrm{C}$ but is not too steep as to pose difficulties with the numerical solution. The numerical scheme is based on the controlvolume methodology of Patankar (1980) and has been described in detail in Jordan (1991). Thermal conductivity $k_{\mathrm{s}}$ is estimated from snow density as

$$
k_{\mathrm{s}}=k_{\mathrm{a}}+\left(7.75 \times 10^{-5} \rho_{\mathrm{s}}+1.105 \times 10^{-6} \rho_{\mathrm{s}}^{2}\right)\left(k_{\mathrm{i}}-k_{\mathrm{a}}\right)
$$

where $k_{\mathrm{a}}$ and $k_{\mathrm{i}}$ are the thermal conductivities of air and ice, respectively, and the coefficients have been selected so that Equation (3) fits the data of Yen (1962) and extrapolates to the conductivity of ice. Latent-heat effects due to the diffusion and sublimation of water vapor are incorporated in the effective thermal conductivity as

$$
k_{\mathrm{cs}}=k_{\mathrm{s}}+L_{\mathrm{v}} D_{\mathrm{e}} \frac{\partial \rho_{\mathrm{v}}}{\partial T}
$$

where $L_{\mathrm{v}}$ is the latent heat of sublimation, $D_{\mathrm{e}}$ is the effective diffusion coefficient of water vapor through snow and $\rho_{\mathrm{v}}$ is the water-vapor density.

The surface-energy flux $F_{\text {top }}$ (positive upwards) combines the net solar flux $\left(F_{\text {solar }}\right)$, the net longwaveradiation flux $\left(F_{\mathrm{ir}}\right)$ and the turbulent-energy fluxes of sensible $\left(F_{\text {sen }}\right)$ and latent heat $\left(F_{\text {lat }}\right)$, giving

$$
F_{\text {top }}=F_{\text {ir }}+F_{\text {solar }}+F_{\text {sen }}+F_{\text {lat }} .
$$

Measurements of the downwelling longwave flux were unavailable and are estimated from a formula based on the equation of Idso (1981). As is customary, the emitted component of the upwelling longwave flux is computed from the Stefan-Boltzmann equation, in which the snow emissivity is taken as 0.97 (Jordan and others, 1989). The turbulent fluxes are computed as Andreas and Murphy, 1986):

$$
F_{\text {sen }}=-\rho_{\mathrm{a}} c_{\mathrm{a}} C_{\mathrm{H}} w\left(T_{\mathrm{a}}-T^{n}\right)
$$

and

$$
F_{\text {lat }}=-L_{\mathrm{v}} C_{\mathrm{E}} w\left(\rho_{\mathrm{v}, \mathrm{a}}-\rho_{\mathrm{v}}{ }^{n}\right)
$$

where $\rho_{\mathrm{a}}$ is the air density, $c_{\mathrm{a}}$ is the specific heat of air at constant pressure, $C_{\mathrm{H}}$ is the bulk-transfer coefficient for sensible heat, $T_{\mathrm{a}}$ is the air temperature, $T^{n}$ is the temperature of the surface-control volume, $n, C_{\mathrm{E}}$ is the bulk-transfer coefficient for latent heat, $w$ is the wind speed, $\rho_{\mathrm{v}}{ }^{n}$ is the water-vapor density of the surfacecontrol volume and $\rho_{v, a}$ is the water-vapor density in air, computed from the relative humidity. The bulk-transfer coefficient for sensible heat is computed from the roughness length $z_{0}$, giving for neutral stability

$$
C_{\mathrm{HN}}=\frac{k^{2}}{\left[\ln \left(\frac{Z^{\prime}}{z_{0}}\right)\right]^{2}}
$$


where $Z^{\prime}$ is the observation height above the snow interface. A value of $0.007 \mathrm{~m}$ is used for $z_{0}$. The bulktransfer coefficient for latent heat at neutral stability $C_{\mathrm{EN}}$ is taken as $0.7 C_{\mathrm{HN}}$. For unstable atmospheric conditions, the standard stability adjustment is made to $C_{\mathrm{EN}}$ and $C_{\mathrm{HN}}$ (Large and Pond, 1982) but, for stable conditions, the correction is omitted, since it was found to degrade the performance of the model significantly.

The magnitude of the solar-absorption term depends primarily on the intensity, angle and spectral composition of the incident radiation, and on snow albedo, optical depth and grain diameter. As a first approximation, incident solar energy is assumed to be diffuse and isotropic. The heating rate is computed using a net bulk-extinction coefficient $\beta_{\text {ext }}$ Grenfell and Maykut, 1977; Brandt and Warren, 1993) defined as

$$
\begin{gathered}
\beta_{\mathrm{ext}}=\int \beta_{\lambda}\left[F_{\lambda}(0) \exp ^{-\beta_{\lambda}}(h-z)\right] \mathrm{d} \lambda / \\
\\
\int\left[F_{\lambda}(0) \exp ^{-\beta_{\lambda}}(h-z)\right] \mathrm{d} \lambda
\end{gathered}
$$

where $\beta_{\lambda}$ is the spectral flux-extinction coefficient, $F_{\lambda}(0)$ is the net spectral radiation at the snow surface and $h$ is the snow depth. The spectral integration is simplified into two broad bands corresponding roughly to the wavelength ranges of $0.4-1.12 \mu \mathrm{m}$ and $1.12-2.4 \mu \mathrm{m}$. Radiation within the lower-energy band is assumed to be totally absorbed within the top-control volume. That within the higher-energy band is assumed to decay according to Beer's law, using a net asymptotic bulk-extinction coefficient $\beta_{\infty}$ computed from the formula of Bohren and Barkstrom (1974):

$$
\left.\beta_{\text {ext }} \text { (high-energy band }\right)=\beta_{\infty}=\frac{C \rho_{\mathrm{s}}}{\sqrt{d}} .
$$

The empirically derived value of 0.003795 suggested by Anderson $(1976)$ is used for the adjustable parameter $C$. Combining the contributions from the two energy bands, the discretized energy gain due to solar heating within the snow cover is

$$
\begin{aligned}
\Delta F_{\text {solar }}{ }^{n} & =F(0)_{\text {solar }}-F_{\text {solar }^{n-\frac{1}{2}}} \\
& =F(0)_{\text {solar }}\left(1-f \exp ^{-\beta_{x} \Delta z}\right)
\end{aligned}
$$

for the surface-control volume, and

$$
\begin{aligned}
\Delta F_{\text {solar }^{j}} & =F_{\text {solar }^{j+\frac{1}{2}}}-F_{\text {solar }^{j-\frac{1}{2}}} \\
& =F_{\text {solar }^{j+\frac{1}{2}}}\left(1-\exp ^{\beta_{\infty} \Delta z}\right)^{j}
\end{aligned}
$$

for the interior control volumes $j$, where $F^{j+\frac{1}{2}}$ is the net solar radiation at the upper boundary of control volume $j$ and $f$ is the fraction of net solar radiation in the higherenergy band. Since heat fluxes are defined as positive in the upward direction, a negative value for the change in solar radiation $\Delta F_{\text {solar }}$ corresponds to absorption of energy by the snow cover. Although the fraction $f$ will vary with cloud cover and snow characteristics, a constant value 0.46 is used here, which corresponds to the best fit between predicted and estimated surface temperatures for the standard $10 \mathrm{~d}$ test period used in validating the model.

\section{MODEL SIMULATIONS}

Temperature and liquid-water profiles in the snow cover were simulated for 1100-1900 h on 1 March 1993, which contained the period of melt. Values of snow density and grain-size used in the simulation are provided by the profiles shown in Table 1. Within the two upper layers, a control volume thickness of $0.5 \mathrm{~cm}$ was used. The total snow depth of $34 \mathrm{~cm}$ was sufficiently deep that the snowpack appeared semi-infinite to solar radiation. The simulation was begun at $1800 \mathrm{~h}$ on the previous day to allow the temperature profile to come to equilibrium prior to the period of interest. The observed temperatures at $0900 \mathrm{~h}$ were used to verify the simulation and compared favorably. Values for the thermal and effective thermal conductivity at $1100 \mathrm{~h}$ are shown in Table 1 and were computed from Equations (3) and (4). The thermal conductivity of the upper layer is relatively low, typical of low-density snow, and latent-heat changes due to the diffusion and sublimation of water vapor account for about $50 \%$ of the effective thermal conductivity. A summary of the surface-energy components for the simulation period is shown in Table 2, computed from meteorological observations recorded at $15 \mathrm{~min}$ intervals and fractional cloud-cover observations from a nearby airport. The spectrally integrated albedo for 1 March computed as the ratio of upwelling to downwelling measurements of solar radiation) is plotted in Figure 5 and averaged 0.81 for the day. $A$ rise in albedo in the morning generally corresponded to a period of increased cloud cover, when the spectral composition of the incident radiation was shifted towards the shorter wavelengths.

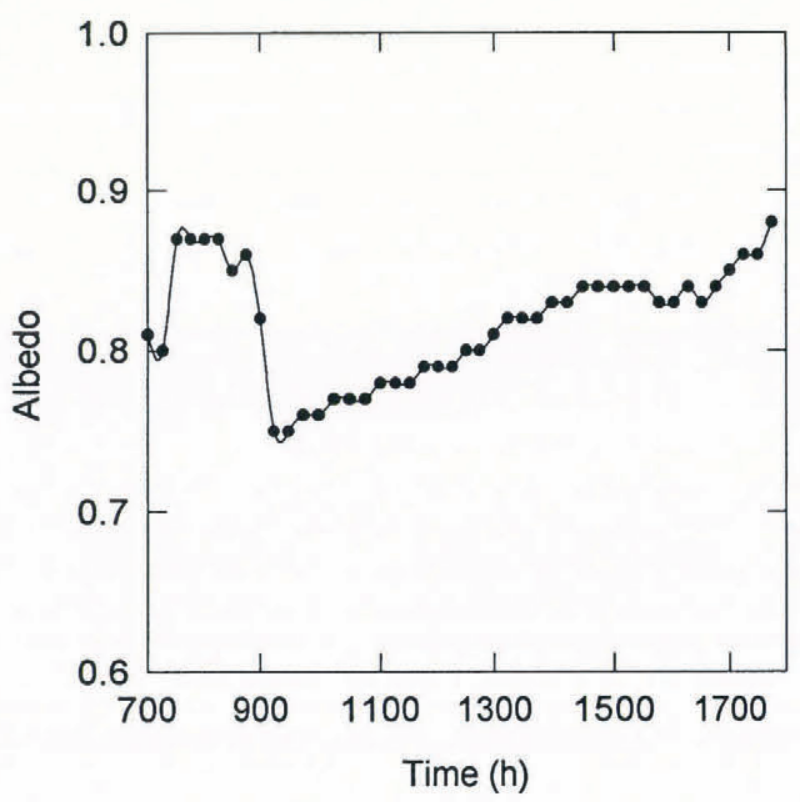

Fig. 5. Spectrally integrated albedo of snow (ratio of upwelling to downwelling measurements of solar radiation from Eppley pyranometers). 1 March 1993, Hanover, New Hampshire, U.S.A.

Hourly predictions of volumetric liquid-water content are shown in Figure 6. The simulation generated output on a $15 \mathrm{~min}$ basis but for illustrative purposes only the 
Table 2. Summary of the surface-energy components for the simulation period

\begin{tabular}{|c|c|c|c|c|}
\hline $\begin{array}{c}\text { Time } \\
\mathrm{h}\end{array}$ & $\begin{array}{l}\text { Net solar radiation } \\
\qquad \mathrm{W} \mathrm{m}^{-2}\end{array}$ & $\begin{array}{l}\text { Nel longwave radiation } \\
\qquad \mathrm{W} \mathrm{m}^{-2}\end{array}$ & $\begin{array}{c}\text { Sensible-heal transfer } \\
\qquad \mathrm{W} \mathrm{m}^{-2}\end{array}$ & $\begin{array}{l}\text { Latent-heat transfer } \\
\qquad \mathrm{W} \mathrm{m}^{-2}\end{array}$ \\
\hline 1100 & 145.700 & -78.500 & -1.800 & -27.300 \\
\hline 1115 & 145.800 & -80.300 & -3.300 & -21.800 \\
\hline 1130 & 147.100 & -80.500 & -2.500 & -28.900 \\
\hline 1145 & 147.900 & -88.300 & -1.600 & -22.400 \\
\hline 1200 & 147.100 & -88.600 & 0.900 & -24.500 \\
\hline 1215 & 145.000 & 90.400 & -1.300 & -15.800 \\
\hline 1230 & 140.200 & -90.100 & 0.200 & -17.000 \\
\hline 1245 & 133.900 & 82.200 & 1.700 & -21.900 \\
\hline 1300 & 127.000 & -79.700 & 7.800 & -27.700 \\
\hline 1315 & 122.000 & -77.800 & 16.100 & -34.300 \\
\hline 1330 & 115.100 & -76.500 & 21.300 & -36.100 \\
\hline 1345 & 108.100 & -75.800 & 18.700 & -25.700 \\
\hline 1400 & 101.100 & -74.400 & 28.100 & -34.300 \\
\hline 1415 & 94.100 & -73.300 & 32.300 & -34.400 \\
\hline 1430 & 85.100 & -71.200 & 56.200 & -52.100 \\
\hline 1445 & 78.100 & -83.300 & 78.200 & 60.600 \\
\hline 1500 & 71.100 & -82.500 & 77.700 & -56.200 \\
\hline 1515 & 62.800 & -81.600 & 73.800 & 48.700 \\
\hline 1530 & 57.200 & -80.600 & 70.000 & -42.600 \\
\hline 1545 & 51.600 & -80.400 & 81.400 & -49.500 \\
\hline 1600 & 45.300 & -79.100 & 70.200 & -37.300 \\
\hline 1615 & 38.300 & -79.800 & 99.700 & -59.000 \\
\hline 1630 & 30.000 & -79.000 & 93.200 & -50.500 \\
\hline 1645 & 23.700 & -78.600 & 102.000 & -53.900 \\
\hline 1700 & 23.700 & -78.400 & 95.300 & -48.400 \\
\hline 1715 & 20.200 & -77.400 & 82.200 & -37.200 \\
\hline 1730 & 2.800 & -73.900 & 64.100 & -19.100 \\
\hline 1745 & 0.700 & -71.000 & 46.900 & -8.700 \\
\hline 1800 & 0.000 & -70.500 & 49.600 & -8.200 \\
\hline 1815 & 0.000 & -66.200 & 27.400 & -1.300 \\
\hline 1830 & 0.000 & -65.700 & 34.700 & -1.200 \\
\hline 1845 & 0.000 & -60.900 & 18.000 & 0.000 \\
\hline
\end{tabular}

half-hourly values are plotted. Sub-surface melt is first predicted at $1215 \mathrm{~h}$ at a depth of about $2.75 \mathrm{~cm}$ and reaches a maximum of $2.06 \%$ at $1630 \mathrm{~h}$ at a depth of $4.25 \mathrm{~cm}$. Although the maximum coincidentally occurred at the top of the underlying denser snow layer, a later run on homogeneous snow (described below) showed a maximum at the same depth. The timing of melt agrees closely with that of $1240 \mathrm{~h}$ observed with the radar. The top of the simulated melt layer occurred at about $2.75 \mathrm{~cm}$ depth, somewhat below the observed depth of $2.0 \mathrm{~cm}$. At around $1545 \mathrm{~h}$, the calculated total volume of liquid water in the snow cover reaches a maximum, about $1 \mathrm{~h}$ later than the observed time of $1440 \mathrm{~h}$ (when the radar return from the ice layer was at a minimum). Temperature profiles on the half-hour are shown in Figure 7. A maximum surface temperature of $-1.5^{\circ} \mathrm{C}$ is reached at $1430 \mathrm{~h}$. As can be seen in Figure 8 , the heat gained by the top-control volume from the external sources of radiation and turbulent transfer from the atmosphere is negative. Therefore, any warming of the snow surface must be through conduction of heat from the underlying region of elevated temperature, which in turn is warmed by solar absorption. After sunset, the snow surface cools rapidly, dropping to $-9 \mathrm{C}$ by $1830 \mathrm{~h}$. Later in the afternoon, the melt layer is calculated to freeze, both from the top down and the bottom up, and is completely refrozen by $1845 \mathrm{~h}$. By comparison, radar observations showed the water to have refrozen by $1740 \mathrm{~h}$.

Several alternative simulations were run to test the effect on melt depth of varying snow characteristics and extinction parameters. The following parameters were varied: the high-energy fraction $f$, the constant $C$ in the Bohren and Barkstrom (1974) bulk-extinction equation, snow density, grain-size and roughness length. The depth, timing and magnitude of maximum melt for these runs are summarized in Table 3. In order to test clearly the effect of density, the snow cover was taken as homogeneous for the sensitivity studies.

Trial $l$ is the base-line simulation and is the same as the case described above, except that the snow characteristics are taken uniformly as those of the top layer. Accordingly, the density is $130 \mathrm{~kg} \mathrm{~m}^{-3}$ and the grain-size is $0.5 \mathrm{~mm}$. The timing and depth of maximum melt are the same as for the layered simulation but the magnitude is 


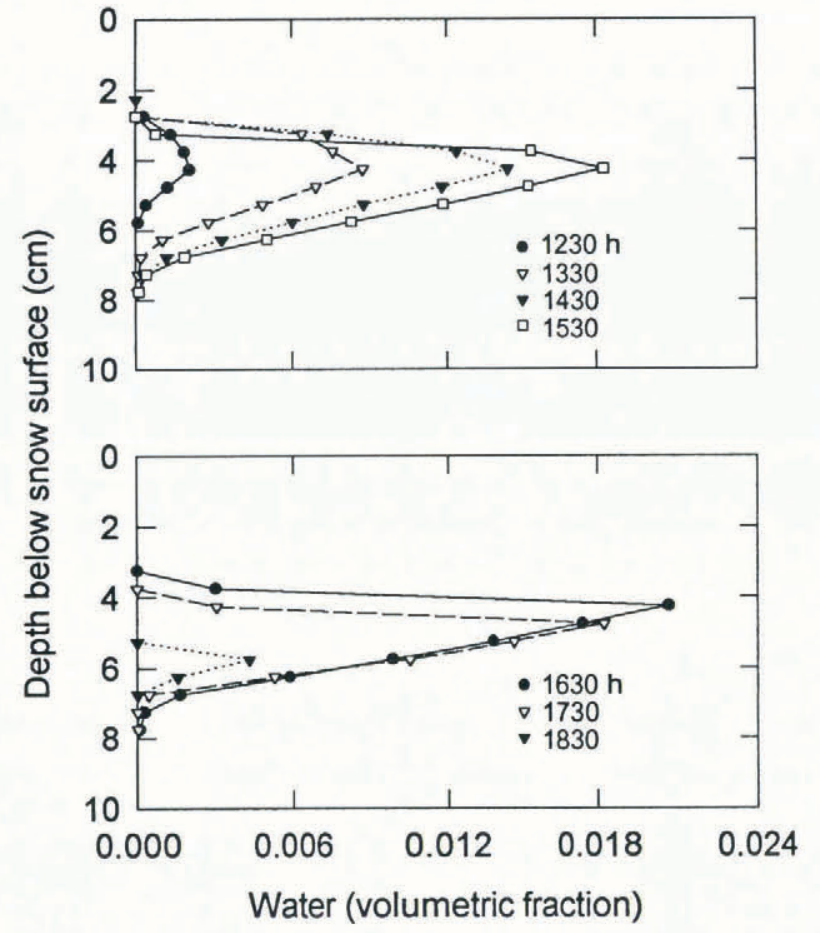

Fig. 6. Hourly predictions of volumetric liquid-water contenl. Simulation is initialized with the snow characteristics in Table 1.

less because less energy is absorbed by the uniformly lighter snow (recall that previously the maximum has occurred at the top of the older snow layer). In trials 2 and 3, the fraction of radiation "dumped" in the topcontrol volume is varied. An approximate fraction of net radiation in the $1.122 .4 \mu \mathrm{m}$ band was computed by

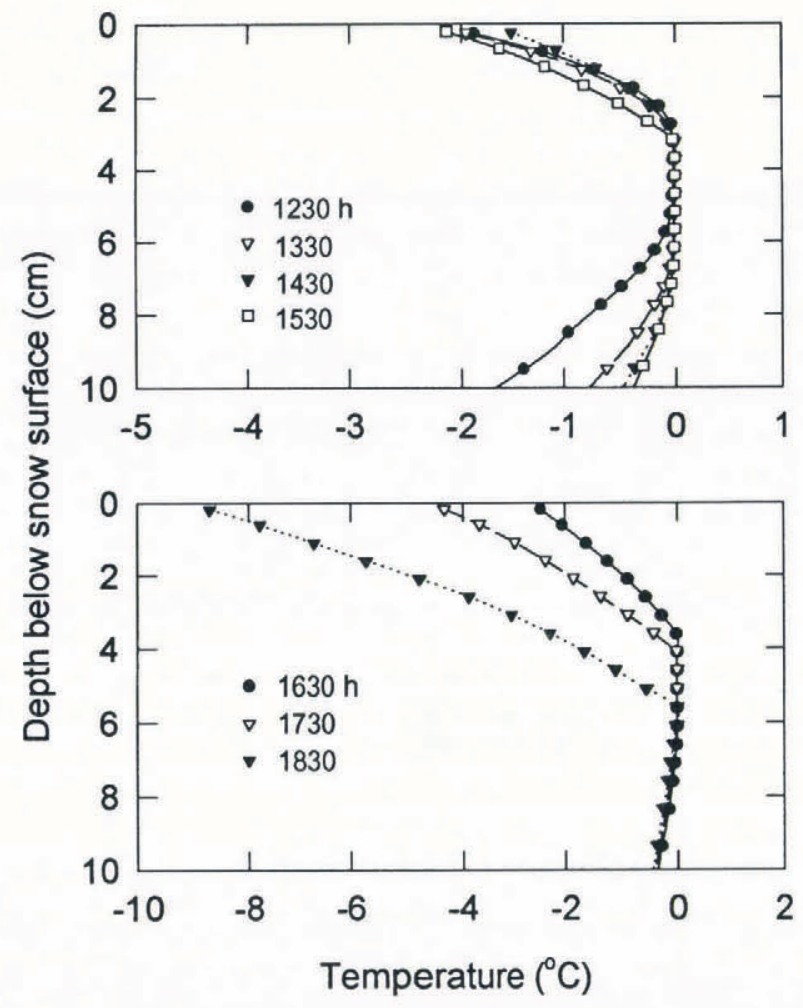

Fig. 7. Simulated temperature profiles on an hourly basis.

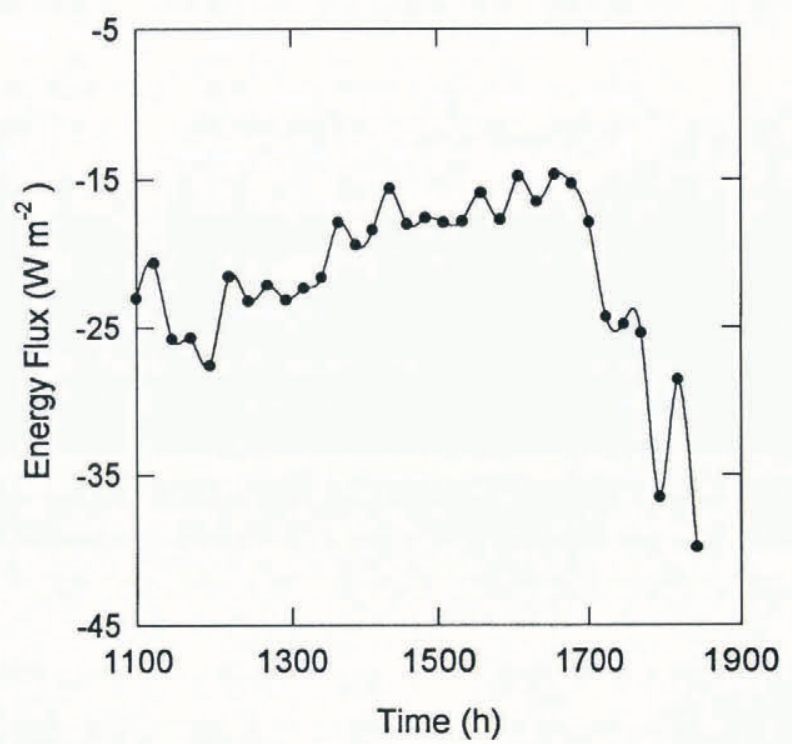

Fig. 8. External energy flux affecting top-control volume (net longwave, radiation sensible- and latent-heal fluxes, solar radiation absorbed by top-control volume).

convolving the incident spectral-irradiance data of Grenfell and Perovich (1984) for sparse clouds (case b) with spectral albedos estimated from the modified twostream procedure of Choudhury and Chang (1979). In the integration procedure, a spectral resolution of $0.005 \mu \mathrm{m}$ was used and the indices of refraction for ice were taken from Warren (1984). The resulting fraction of 0.53 agreed closely with the value of 0.54 used in the baseline case. Increasing the energy dumped in the topcontrol volume to 0.75 resulted in no melt and decreasing it to 0.25 markedly increased the amount of sub-surface liquid water.

The net bulk-extinction coefficient is varied in trials 4 and 5 . For the base-line case, trial 4 and trial $5, B_{\infty}$ computes as $22.06,11.63$ and $58.13 \mathrm{~m}^{-1}$, respectively. Increasing the extinction coefficient (trial 5 ) resulted in a shallower melt depth and an earlier occurrence of the peak. The depth of the melt layer observed with the radar was best replicated using a value of about $40 \mathrm{~m}^{-1}$ for $B_{\infty}$. A further trial was conducted in which the two-band routine in SNTHERM was replaced with a simplified four-band model, in order to test whether a narrower spectral resolution would improve the simulation. The spectrum was divided into bands of $0.4-0.93,0.93-1.12$, $1.12-1.39$ and $1.39-2.4 \mu \mathrm{m}$ and effective bulk-extinction coefficients were computed from Equation (9), using the depth $(h-z)$ at which half the radiation within the band was absorbed. Spectral albedos and spectral bulkextinction coefficients used in the integration were estimated from the asymptotic formulas of Choudhury and Chang (1979). The resulting estimates of $\beta_{\infty}$ for the four bands (high to low energy) were $7.50,33.46,77.29$ and $516.64 \mathrm{~m}^{-1}$. The depth of the upper edge of the melt zone for the four-band solution was unchanged in comparison with the base-line case but the maximum melt occurred at the slightly shallower depth of $3.75 \mathrm{~cm}$. While the simulation was marginally improved, refining the spectral resolution did not appear to account for all the residual error. A plausible explanation for the 
Table 3. Depth, liming and magnitude of maximum mell for variations in $f, C$, snow density, grain-size and roughness length

\begin{tabular}{rrrrrrrrl}
\hline Trial & $1-f$ & $\begin{array}{c}C \times 10^{3} \\
\mathrm{~m}^{2.5} \mathrm{~kg}^{-1}\end{array}$ & $\begin{array}{c}\rho_{\mathrm{s}} \\
\mathrm{kg} \mathrm{m}^{3}\end{array}$ & $\begin{array}{c}d \\
\mathrm{~mm}\end{array}$ & $\begin{array}{c}z_{0} \\
\mathrm{~m}\end{array}$ & $\begin{array}{c}\text { Depth } \\
\mathrm{cm}\end{array}$ & $\begin{array}{c}\text { Time } \\
\mathrm{h}\end{array}$ & $\begin{array}{c}\text { Liquid water } \\
\text { per cent }\end{array}$ \\
\hline 1 & 0.54 & 3.795 & 130 & 0.5 & 0.007 & 4.25 & 1630 & 1.64 \\
2 & 0.75 & 3.795 & 130 & 0.5 & 0.007 & - & - & None \\
3 & 0.25 & 3.795 & 130 & 0.5 & 0.007 & 4.25 & 1730 & 3.89 \\
4 & 0.56 & 2.000 & 130 & 0.5 & 0.007 & 5.75 & 1645 & 1.07 \\
5 & 0.54 & 10.000 & 130 & 0.5 & 0.007 & 2.25 & 1430 & 1.02 \\
6 & 0.54 & 3.795 & 130 & 1.0 & 0.007 & 4.75 & 1615 & 1.35 \\
7 & 0.54 & 3.795 & 250 & 0.5 & 0.007 & - & - & None \\
8 & 0.54 & 3.795 & 250 & 1.0 & 0.007 & - & - & None \\
9 & 0.54 & 3.795 & 130 & 0.5 & 0.001 & 3.75 & 1545 & 1.77 \\
10 & 0.54 & 3.795 & 130 & 0.5 & 0.050 & 4.75 & 1715 & 1.48 \\
\hline
\end{tabular}

discrepancy between theory and observation is that the snow at the Hanover site was slightly contaminated, leading to somewhat higher extinction coefficients than expected for pure snow. Because the natural snow cover was inhomogeneous, it is also possible that a multilayered model, such as that described by Perovich (1989), is necessary accurately to model sub-surface melt.

Varying the grain-size by itself (trial 6 ) had the same effect as changing the parameter $C$, since both parameters affect the magnitude of $\beta_{\infty}$. A computed all-wave albedo of 0.83 was close to the observed value of 0.81 , giving us confidence that the estimated grain-size of $0.5 \mathrm{~mm}$ was reasonable. If the site were contaminated, however, it is possible that the actual grain-size was smaller. The allwave albedo was computed by integrating the spectral irradiance data of Grenfell and Perovich (1984) with spectral albedos computed from the formula of Choudhury and Chang (1979), again using a $0.005 \mu \mathrm{m}$ spectral resolution.

When the snow density was increased to $250 \mathrm{~kg} \mathrm{~m}^{-3}$ (trials 7 and 8), no melt occurred. Increasing the density increased both the extinction coefficient and the thermal conductivity but the thermal conductivity appeared to influence the occurrence of sub-surface melt more strongly. Because of the density-dependence in Equation (3), the effective thermal conductivity was approximately 2.5 times that of the base-line case and the region of elevated temperature was more rapidly cooled by conduction. The sub-surface temperature for trial 7 was still elevated (about $0.7^{\circ} \mathrm{C}$ above that of the surface) but never reached the melting point.

The depth of the melt zone was moderately sensitive to changes in surface roughness, as illustrated by trials 9 and 10. The surface roughness governs the magnitude of turbulent-energy exchange between the snow cover and the overlying air. Since the combined turbulent fluxes are negative until $1430 \mathrm{~h}$, larger and smaller values of $z_{0}$ will result in greater and lesser cooling of the surface, respectively. Correspondingly, the melt zone shifted upward and downward for trials 9 and 10. The radar observations are best matched with the shorter roughness length of $1 \mathrm{~mm}$, both in the location and earlier timing of the melt. In addition to uncertainties in the computation of the turbulent fluxes, the estimated downwelling longwave flux may have been in error due to the approximate cloud-cover values used in the simulation.

\section{CONGLUSIONS}

A high-resolution FMCW radar has been used to detect sub-surface melting in a seasonal snow cover. A onedimensional mass- and energy-balance model using a simple two-band resolution for the solar spectrum is shown to be effective in reproducing the experimental results. Additional model simulations were run to investigate the effects of varying snow characteristsics and solar-extinction parameters on the sub-surface melt characteristics. In agreement with Brandt and Warren (1993), sub-surface melt in the model simulations was limited to low-density snow. It is reasonable to conclude that on calm, clear days when the air temperature is near freezing, sub-surface melting is likely to occur in lowdensity snow. Since these conditions are not uncommon in a seasonal snow cover, the importance of sub-surface melt and its effect on the near-surface snow properties and processes should not be minimized.

\section{ACKNOWLEDGEMENTS}

We are grateful to Dr S. Colbeck and Dr D. Perovich for their helpful comments and suggestions regarding this report. We also wish to thank Ms N. Kent for assistance in running the model simulations and producing the graphs, and $\mathrm{Mr} \mathrm{B}$. Harrington and $\mathrm{Mr}$ J. Fiori for providing automated meteorological support.

\section{REFERENCES}

Akitaya, E. and H. Shimizu. 1987. Observations of weak layers in a snow cover. Low Temp. Sci., Ser A 46, 67-75. [In Japanese with English summary.]

Anderson, E. A. 1976. A point energy and mass balance model of a snow cover. NOAA Tech. Rep. NWS-19.

Andreas, E. L. and B. Murphy. 1986. Bulk transfer coeflicients for heat 
and momentum over leads and polynyas. F. Phys. Oceanogr., 16(11), $1875-1883$.

Bohren, C.F. and B.R. Barkstrom. 1974. Theory of the optical properties of snow. J. Geophys. Res., 79 (30),4527-4535.

Brandt, R.E. and S.G. Warren. 1993. Solar-heating rates and temperature profiles in Antarctic snow and ice. J. Glaciol., 39(131), $99-110$.

Brun, E., E. Martin, V. Simon, C. Gendre and C. Coleou. 1989. An energy and mass model of snow cover suitable for operational avalanche forecasting. J. Glaciol., 35 (121), 333-342.

Choudhury, B.J. and A. T. C. Chang. 1979. Two-stream theory of reflectance of snow. IEEE Trans. Geosci. Electron., GE-17 (3), 63-68.

Colbeck, S.C. 1989. Snow-crystal growth with varying surface temperatures and radiation penetration. F. Glaciol., 35 (119), 23-29.

Grenfell, T.C. and G. A. Maykut. 1977. The optical properties of ice and snow in the Arctic Basin. J. Glaciol., 18 (80), 445-463.

Grenfell, T. C. and D. K. Perovich. 1984. Spectral albedos of sea ice and incident solar irradiance in the southern Beaufort Sea. J. Geophys. Res., 89 C3), 3573-3580.

Greuell, J. W. and T. Konzelmann. 1994. Numerical modeling of the energy balance and the englacial temperature of the Greenland ice sheet: calculations for the ETH-Camp location (West Greenland, $1155 \mathrm{~m}$ a.s.l.). Global and Planetary Change, 9 (1-2), 91-114.

Idso, S. B. 1981. A set of equations for full spectrum and $8-14 \mu \mathrm{m}$ and $10.5-12.5 \mu \mathrm{m}$ thermal radiation from cloudless skies. Water Resour. Res., 17, 295-304.
Izumi, K. 1989. Effects of solar radiation on the formation of weak wet snow. Ann. Glaciol., 13, 120-123.

Jordan, R. 1991. A one-dimensional temperature model for a snow cover. CRREL Spec. Rep. 91-16.

Jordan, R., H. O'Brien and M. R. Albert. 1989. Snow as a thermal background: preliminary results from the 1987 field test. CRREL Spec. Rep. 89-7, 5-24.

Large, W.G. and S. Pond. 1981. Open ocean momentum flux measurements in moderate to strong winds. J. Phys. Oceanogr., 11, 324-336.

Marshall, S. E. and S. G. Warren. 1987. Parameterization of snow albedo for climate models. International Association of Hydrological Sciences Publication 166 (Symposium at Vancouver 1987 Large Scale Effects of Seasonal Snow Cover), 43-50.

Pantankar, S. V. 1980. Numerical heat transfer and fluid flow. New York, etc., Hemisphere Publishing.

Perovich, D. K. 1989. A two-stream multilayer, spectral radiative transfer model for sea ice. CRREL Rep. 89-15.

Schlatter, T. W. 1972. The local surface energy balance and subsurface temperature regime in Antarctica. J. Appl. Meteorol., 11(10), 10481062.

Warren, S. G. 1984. Optical constants of ice from the ultraviolet to the microwave. Appl. Opt., 23 (8), 1206-1225.

Yen, Y. -C. 1962. Effective thermal conductivity of ventilated snow. $\mathcal{f}$. Geophys. Res., 67 (3), 1091-1098.

MS received 22 November 1993 and accepted in revised form 24 January 1995 